\title{
Higher CYP2E1 Activity Correlates with Hepatocarcinogenesis Induced by Diethylnitrosamine
}

\author{
Jie Gao, ${ }^{1}$ Zhao Wang, ${ }^{1}$ Gao-Ju Wang, ${ }^{1}$ Hong-Xin Zhang, Na Gao, Jie Wang, Cai-E. Wang, \\ Zhao Chang, Yan Fang, Yun-Fei Zhang, Jun Zhou, Han Jin, and Hai-Ling Qiao \\ Institute of Clinical Pharmacology, Zhengzhou University, Zhengzhou, Henan, China (J.G., Z.W., G.-J.W., H.-X.Z., N.G., J.W., \\ C.-E.W., Z.C., Y.F., Y.-F.Z., J.Z., H.J., H.-L.Q.); First Affiliated Hospital of Zhengzhou University, Zhengzhou, Henan, China (H.-X.Z.); \\ Affiliated Cancer Hospital of Zhengzhou University, Zhengzhou, Henan, China (Y.-F.Z.); and Affiliated Provincial People's \\ Hospital of Zhengzhou University, Zhengzhou, Henan, China (J.Z.)
}

Received October 6, 2017; accepted January 8, 2018

\begin{abstract}
Hepatocellular carcinoma ( $\mathrm{HCC}$ ) is one of the most common types of primary liver cancer and the third most frequent cause of cancer death worldwide. Diethylnitrosamine (DEN) is one of the recognized risk factors for hepatocarcinogenesis likely due to CYP2E1-mediated metabolic activation. However, CYP2E1-mediated DEN metabolic activity in non-neoplastic liver tissue from HCC patients has not been determined; the role of CYP2E1 activity, in particular CYP2E1 constitutive activity and CYP2E1 inhibited activity, with respect to the hepatocarcinogenesis induced by DEN is not yet clear. Herein, we determined CYP2E1-mediated DEN metabolic activity in non-neoplastic liver tissue from HCC patients and found that CYP2E1-mediated DEN metabolic activity was significantly elevated with a $43.3 \%$ positive rate,
\end{abstract}

and clinicopathologic parameters did not affect the activity. Then, using a Sprague-Dawley rat liver tumor model induced by DEN, the relationship between CYP2E1 constitutive/inhibited activity and hepatocarcinogenesis was explored. The results showed that the CYP2E1 constitutive activity was strongly correlated with tumor incidence and severity of liver tumorigenesis (nodule numbers and size), whereas inhibition of CYP2E1 activity decreased hepatocyte proliferation, liver injury, and liver carcinogenesis in the presence of DEN. In conclusion, the higher CYP2E1 activity would lead to an increased incidence of $\mathrm{HCC}$ as a result of CYP2E1-mediated DEN activation. Therefore, higher CYP2E1 activity might be a risk factor for $\mathrm{HCC}$ induced by DEN.

\section{Introduction}

Hepatocellular carcinoma (HCC) is one of the most common types of primary liver cancer and the third leading cause of cancer-related deaths globally (El-Serag and Rudolph, 2007; McClendon et al., 2011; Su et al., 2015). In addition to chronic infection with hepatitis B virus (HBV) and hepatitis C virus, chemical carcinogens (e.g., $N$-alkylnitrosamines, aflatoxin B1, etc.) are also risk factors for HCC, especially in China and other developing countries (Bosetti et al., 2008; Ferlay et al., 2010; Abu Dayyeh et al., 2011; El-Serag, 2011; Yoshimoto et al., 2013; Nault et al., 2015). There is considerable evidence to support the view that $N$-alkylnitrosamines, which are some of the most potent chemical carcinogens and are present widely in the environment, can induce various cancers in animals and maybe even in humans (Bartsch and Montesano, 1984; Hoffmann and Hecht, 1985; Mirvish, 1995). Of the many $\mathrm{N}$-alkylnitrosamines found in food and the environment,

This work was supported by the National Natural Science Foundation of China (Nos. 81473279 and 81673507 to H.-L.Q).

${ }^{1}$ J.G., Z.W., and G.-J.W. contributed equally to this work.

https://doi.org/10.1124/jpet.117.245555. diethylnitrosamine (DEN) is a level I carcinogen and has been found widely in various products, such as meat (Herrmann et al., 2015), tobacco smoke (Hengstler et al., 2003), and food color additives (Tsuda et al., 2001). Although diet contributes greatly to DEN exposure, only a handful of people will develop HCC. Why there is this discrepancy between exposure and induction of cancer is largely unknown.

CYP2E1, mainly expressed in the liver, plays a critical role in the activation of many known environmental toxicants as well as cancer suspects, such as benzene, ethanol, carbon tetrachloride, and vinyl chloride (Guengerich et al., 1991; Gonzalez, 2005; Kang et al., 2007; Zanger and Schwab, 2013). Because of the particular relevance of CYP2E1 for toxicology due to its role in the metabolic activation of procarcinogens, a growing body of research has focused on the association of CYP2E1 with various cancers (Yu et al., 1995; DruesnePecollo et al., 2009; Trafalis et al., 2010; Wang et al., 2010; Boccia et al., 2015). In addition, CYP2E1 has been suggested to be one of the major enzymes involved in the metabolic activation of dimethylnitrosamine and DEN to genotoxic products, which alkylate nucleic acids irreversibly, in rat liver microsomes and recombinase systems (Yoo et al., 1990;

ABBREVIATIONS: $\mathrm{AUC}_{0-\mathrm{t}}$, area under curve; CL/F, apparent clearance; CMZ, clomethiazole; CZX, chlorzoxazone; DEN, diethylnitrosamine; HBV, hepatitis B virus; HCC, hepatocellular carcinoma; HPLC, high-pressure liquid chromatography; PCNA, proliferating cell nuclear antigen; SD, Sprague-Dawley; $t_{1 / 2}$, half-life. 
Yamazaki et al., 1992; Kushida et al., 2000). Given CYP2E1mediated nitrosamine activation can lead to hepatocarcinogenesis, some research has studied the association of CYP2E1 with HCC (Yu et al., 1995; Kang et al., 2007; Liu et al., 2014; Boccia et al., 2015). However, there are some questions given that CYP2E1 content, rather than CYP2E1 activity, was linked to hepatocarcinogenesis (Kang et al., 2007; Kim et al., 2015). Actually, there was only weak correlation between CYP2E1 content and its activity (Gao et al., 2016b). Therefore, the importance of CYP2E1 activity in hepatocarcinogenesis induced by DEN was explored in this study.

Our previous studies found that CYP2E1-mediated probe drug [chlorzoxazone (CZX)] clearance revealed 20.3-fold and 13.1-fold individual variations in control subjects and HCC patients, respectively (Gao et al., 2016b; Zhou et al., 2016). CYP2E1-mediated probe clearance was markedly increased in HCC patients, whereas metabolism by CYP2C9 and CYP2D6 did not change, and probe drug clearance for CYP1A2, CYP2A6, CYP2B6, CYP2C8, CYP2C19, and CYP3A4/5 was decreased in these patients (Gao et al., 2016a). However, several studies have reported that CYP2E1 activity in vitro and in vivo was clearly decreased or unchanged in patients with simple hepatic cirrhosis (George et al., 1995; Frye et al., 2006). This raises two questions: is CYP2E1-mediated DEN metabolism also increased in non-neoplastic liver tissue from HCC patients, and does higher CYP2E1-mediated DEN metabolism correlate with hepatocarcinogenesis induced by DEN?

To explore the aforementioned questions, we first characterized the CYP2E1-mediated DEN metabolic activity in nonneoplastic liver tissue from HCC patients. Next, using a rat liver tumor model induced by DEN, we examined the correlation between CYP2E1 constitutive activity and hepatocarcinogenesis, and investigated the effect of inhibition of CYP2E1 activity on hepatocarcinogenesis.

\section{Materials and Methods}

Patients and Samples. A total of 67 patients undergoing radical resection of $\mathrm{HCC}$ were identified based on imaging criteria on ultrasonography or computer tomography, and further confirmed by histopathological analysis between March 14, 2013 and July 14, 2014 at First Affiliated Hospital of Zhengzhou University, Affiliated Provincial People's Hospital of Zhengzhou University, and the Affiliated Cancer Hospital of Zhengzhou University. Nonneoplastic liver specimens, which were about $2 \mathrm{~cm}$ from the tumor tissues from these same HCC patients, were obtained and stored in liquid nitrogen within 30 minutes of resection and until use. Normal human liver tissue samples $(n=95)$, confirmed by histopathological examination, were collected from subjects with liver hemangioma, metastatic carcinoma, cholelithiasis, or gallbladder cancer between March 29, 2012 and September 19, 2013 at the aforementioned hospitals. These liver tissues were used as normal liver controls, and these subjects were considered as "control subjects." The Medical Ethics Committee of Zhengzhou University, Zhengzhou, China approved the tissue collection and in vitro metabolism studies, and patients provided written informed consent for the use of all surgically removed tissue specimens used in this study.

CYP2E1 Content. CYP2E1 content was estimated by enzymelinked immunosorbent assay. In brief, $30 \mathrm{mg}$ of liver tissue stored in liquid nitrogen was defrosted on ice and weighed. Phosphate-buffered saline $(0.01 \mathrm{M}, \mathrm{pH}=7.0)$ was added $1: 20(\mathrm{w}: \mathrm{v})$ and then homogenized at $4^{\circ} \mathrm{C}$, followed by centrifugation at $6000 \mathrm{~g}$ for 10 minutes, recovering the supernatant fraction. A $10-\mu$ l aliquot of supernatant was diluted 40-fold for analysis, performed according to standard procedures provided by the manufacturer (Wuxi Donglin Sci \& Tech Development, Jiangsu, China).

Serum $\alpha$-Fetoprotein. Serum $\alpha$-fetoprotein levels were measured by an electrochemiluminescence immunoassay (E170 Analytics; Roche Diagnostics, Indianapolis, IN). The $\alpha$-fetoprotein data included in this analysis were measurements obtained before surgery.

Experimental Animals. Male Sprague-Dawley (SD) rats (160 \pm $20 \mathrm{~g}$, no. 11400700149357), 5 weeks of age, were supplied by Beijing Vital River Laboratory Animal Technology (Beijing, China). All animals were housed in a virus-free facility and maintained in a standard temperature- and light-controlled animal facility and had free access to standard laboratory chow and water. Experiments were initiated after acclimation to these conditions for 1 week. All animal experiments were undertaken in accordance with the National Institutes of Health Guide for the Care and Use of Laboratory Animals, with the approval of the Medical Ethics Committee of Zhengzhou University, Zhengzhou, China.

CYP2E1 Activity. CZX was purchased from the National Institute for Food and Drug Control (Beijing, China), and 6-hydroxychlorzoxazone was from Sigma-Aldrich (St. Louis, MO). DEN was from TCI (Shanghai Shi, China). Aldehyde and 2,4-dinitrophenylhydrazine were from Aladdin (Shanghai).

Human liver microsomes were prepared using the hypothermal differential centrifugation method (Zhang et al., 2015). Microsomal protein concentration was determined according to the Bradford method (Bradford, 1976). The CYP2E1 activities of normal liver samples from control subjects and non-neoplastic liver tissue from HCC patients were determined at a single concentration in individual assays by incubation of $0.3 \mathrm{mg}$ of microsomal protein, $100 \mathrm{mM}$ phosphate buffer (pH 7.4), and substrate (500 $\mu \mathrm{M} \mathrm{CZX} \mathrm{or}$ $160 \mathrm{mM}$ DEN). The mixture was incubated for 5 minutes at $37^{\circ} \mathrm{C}$, and the reaction was initiated by adding $1 \mathrm{mM}$ NADPH. Each reaction was terminated after the specified incubation period by adding $1 \mathrm{ml}$ of ethyl acetate (CZX) or $10 \mu \mathrm{l}$ of perchloric acid (DEN). Incubation conditions were ensured to yield linear metabolite formation with respect to reaction time and protein concentration. 6-Hydroxychlorzoxazone was extracted using $1 \mathrm{ml}$ of ethyl acetate, and the extract was concentrated to dryness under nitrogen and dissolved in mobile phase for analysis by high-pressure liquid chromatography (HPLC) using a Diamonsil $\mathrm{C}_{18}$ column $(5 \mu \mathrm{m}$, $4.6 \times 200 \mathrm{~mm}$; Dikma Technologies, Beijing, China). Samples were eluted with methanol/water $[55: 45(\mathrm{v} / \mathrm{v})]$ at a flow rate of $1.0 \mathrm{ml} / \mathrm{min}$. The eluates were monitored by a UV detector at $287 \mathrm{~nm}$. Known quantities of 6-hydroxychlorzoxazone, added to incubation mixtures in the absence of cofactors, were used as standards. For aldehyde determinations, $100-\mu \mathrm{l}$ aliquots of supernatant after $10 \mu \mathrm{l}$ of perchloric acid precipitation were added in tubes containing $50 \mu \mathrm{l}$ of $1 \mathrm{mg} / \mathrm{ml}$ 2,4-dinitrophenylhydrazine in $6 \mathrm{M} \mathrm{HCl}, 2 \mathrm{ml}$ isooctane, and $2 \mathrm{ml}$ of $3 \mathrm{M}$ sodium acetate. The tubes were vigorously shaken for 20 minutes at $60^{\circ} \mathrm{C}$. Then $1.6 \mathrm{ml}$ of the isooctane layer was dried under nitrogen and dissolved in $200 \mu \mathrm{l}$ of mobile phase for analysis by HPLC using a Diamonsil $\mathrm{C}_{18}$ column $(5 \mu \mathrm{m}, 4.6 \times 200 \mathrm{~mm}$; Dikma Technologies). Samples were eluted with acetonitrile/water [75:25 $(\mathrm{v} / \mathrm{v})$ ] at a flow rate of $1.0 \mathrm{ml} / \mathrm{min}$. The eluates were monitored by a UV detector at $356 \mathrm{~nm}$. Known quantities of aldehyde, added to incubation mixtures in the absence of cofactors, were used as standards.

The CYP2E1 constitutive activity of each rat was determined by measuring toxicokinetic parameters [half-life $\left(t_{1 / 2}\right)$, apparent clearance $(\mathrm{CL} / \mathrm{F})$, area under the curve $\left.\left(\mathrm{AUC}_{0-\mathrm{t}}\right)\right]$ of $\mathrm{DEN}(50 \mathrm{mg} / \mathrm{kg})$, which was administered by intraperitoneal injection to healthy male rats. Blood samples $(0.5 \mathrm{ml})$ were collected before DEN dosing and at $1,4,10,25$, and 60 minutes, and 2.5, 4.5, 7, 10, and 24 hours after DEN dosing by orbital bleeding into heparinized tubes. Plasma was obtained by centrifugation at $4500 \mathrm{rpm}$ for 10 minutes at $4^{\circ} \mathrm{C}$. The plasma was precipitated by $10 \mu \mathrm{l}$ of perchloric acid, vortexed for 
60 seconds, and centrifuged at $4^{\circ} \mathrm{C}$ and $12,000 \mathrm{rpm}$ for 10 minutes, and $10 \mu \mathrm{l}$ of supernatant was analyzed by HPLC using a Diamonsil $\mathrm{C}_{18}$ column ( $5 \mu \mathrm{m}, 4.6 \times 200 \mathrm{~mm}$; Dikma Technologies). Samples were eluted with methanol/water $[50: 50(\mathrm{v} / \mathrm{v})]$ at a flow rate of $1.0 \mathrm{ml} / \mathrm{min}$. The eluates were monitored by a UV detector at $240 \mathrm{~nm}$. Known quantities of DEN, added to incubation mixtures in the absence of cofactors, were used as standards.

The CYP2E1-inhibited activity in the presence of clomethiazole (CMZ) was determined by measuring the toxicokinetic parameters of DEN metabolism $(50 \mathrm{mg} / \mathrm{kg})$, which was injected intraperitoneally immediately after CMZ (10 or $100 \mathrm{mg} / \mathrm{kg}$ ) into healthy male rats. Other experiments were as described earlier.

Rat Liver Tumor Models Induced by DEN. Six-week-old male SD rats were injected intraperitoneally with DEN (50 mg/kg) twice a week in the first 4 weeks and once a week over the next 10 weeks. Saline was used as a vehicle control and was injected into "control" rats at the time of DEN administration. CMZ was used as a CYP2E1 inhibitor in the intervention experiment, in which DEN $(50 \mathrm{mg} / \mathrm{kg})$ was injected immediately after CMZ administration $(10$ or $100 \mathrm{mg} / \mathrm{kg}$ ). At the 19th week, the animals were killed and liver nodules $(\geq 5 \mathrm{~cm})$ were counted and measured (Naito et al., 1986), and the liver was photographed, sectioned, and fixed in $10 \%$ formalin. The remaining portions of the liver were instantly frozen and stored in liquid nitrogen until use.
Histology and Immunohistochemistry. Formalin-fixed samples were embedded in paraffin, cut into 5 - $\mu$ m-thick sections, and stained with hematoxylin and eosin and Masson's trichrome according to standard procedures. Trichrome-stained sections were analyzed to score fibrosis staging according to the method of Ishak (1994). Additional sections were stained with antibodies specific for Ki67 (ab29; Abcam, Cambridge, UK) and proliferating cell nuclear antigen (PCNA) (ab15580; Abcam). After staining for Ki67 and PCNA, positive cells were morphometrically quantified with image-processing software (Image-pro-plus, MEDIA CYBERNETICS, Maryland).

Toxicokinetics Parameters and Statistical Analysis. The Drug and Statistics 3.2.6 (DAS 3.2.6; Mathematical Pharmacology Professional Committee of China, Shanghai, China) was used to calculate $t_{1 / 2}, \mathrm{CL} / \mathrm{F}$, and $\mathrm{AUC}_{0-\mathrm{t}}$ using a one-compartment model. All data were analyzed using the appropriate statistical analysis methods as specified in the table notes or figure legends, with SPSS software (version 17.0; IBM, North Castle, NY). For data with Gaussian distributions, parametric statistical analysis was performed using a one-way analysis of variance with Tamhane's T2 analysis for data with heteroscedasticity. For data sets with skewed distributions, nonparametric statistical analysis was performed using the MannWhitney $U$ test for two groups; the Kruskal-Wallis test followed by Dunn's test was used for multiple comparisons. In addition, significant correlations were determined using two-tailed Pearson correlation

TABLE 1

Demographic and clinicopathologic characteristics of the control subjects $(n=95)$ and HCC patients $(n=67)$

Mann-Whitney $U$ test and $\chi^{2}$ test were used.

\begin{tabular}{|c|c|c|c|}
\hline Clinicopathologic characteristics & Control & $\mathrm{HCC}$ & $P$ Value \\
\hline \multicolumn{4}{|l|}{ Gender } \\
\hline Male $(n, \%)$ & $33(34.7)$ & $56(83.6)$ & $<0.0001$ \\
\hline Female $(n, \%)$ & $62(65.3)$ & $11(16.4)$ & \\
\hline Age (years) & & & 0.011 \\
\hline$\leq 50(n, \%)$ & $63(66.3)$ & $31(46.3)$ & \\
\hline$>50(n, \%)$ & $32(33.7)$ & $36(53.7)$ & \\
\hline Body weight [median (range)] & $63.5(30-92)$ & $66(35-101)$ & 0.11 \\
\hline HBsAg & & & $<0.0001$ \\
\hline Negative $(n, \%)$ & $95(100)$ & $3(4.5)$ & \\
\hline Positive $(n, \%)$ & $0(0)$ & $64(95.5)$ & \\
\hline $\mathrm{HCV}$ & & & 0.23 \\
\hline Negative $(n, \%)$ & $95(100)$ & $66(98.5)$ & \\
\hline Positive $(n, \%)$ & $0(0)$ & $1(1.5)$ & \\
\hline \multicolumn{4}{|l|}{ Diagnosis } \\
\hline & Liver hemangioma $(n=61)$ & $\mathrm{HCC}(n=67)$ & \\
\hline & Metastatic carcinoma $(n=9)$ & & \\
\hline & Cholelithiasis $(n=7)$ & & \\
\hline & Gallbladder cancer & & \\
\hline & $(n=13) ;$ other $(n=5)$ & & \\
\hline Serum AFP (ng/ml) & & & $<0.0001$ \\
\hline$\leq 600(n, \%)$ & $54(100)$ & $31(52.6)$ & \\
\hline$>600(n, \%)$ & $0(0)$ & $28(47.4)$ & \\
\hline \multicolumn{4}{|l|}{ Tumor size $(\mathrm{cm})$} \\
\hline$\leq 5(n, \%)$ & & $16(24.6)$ & \\
\hline$>5(n, \%)$ & & $49(75.4)$ & \\
\hline \multicolumn{4}{|l|}{ Multinodular tumors } \\
\hline Yes $(n, \%)$ & & $26(40.0)$ & \\
\hline No $(n, \%)$ & & $39(60.0)$ & \\
\hline \multicolumn{4}{|l|}{ Tumor grade } \\
\hline $\mathrm{I}$ and II $(n, \%)$ & & $29(44.6)$ & \\
\hline III and IV $(n, \%)$ & & $36(55.4)$ & \\
\hline \multicolumn{4}{|l|}{ Metastasis } \\
\hline Yes $(n, \%)$ & & $4(6.2)$ & \\
\hline No $(n, \%)$ & & $61(93.8)$ & \\
\hline \multicolumn{4}{|l|}{ Portal vein tumor thrombus } \\
\hline Yes $(n, \%)$ & & $16(24.6)$ & \\
\hline No $(n, \%)$ & & $49(75.4)$ & \\
\hline \multicolumn{4}{|l|}{ Splenomegaly } \\
\hline Yes $(n, \%)$ & & $18(27.7)$ & \\
\hline No $(n, \%)$ & & $47(72.3)$ & \\
\hline
\end{tabular}

AFP, alpha-fetoprotein; HBsAg, hepatitis B surface antigen; HCV, hepatitis C virus. 
calculations. The $\chi^{2}$ test was used for comparing clinic-pathologic characteristics in humans and tumor incidence in rats. A $P$ value of 0.05 or less was considered to indicate statistical significance. All graphs were generated using the Photoshop CC 2014 (Adobe, San Jose, CA) and GraphPad Prism 5.04 software package (GraphPad Software, La Jolla, CA).

\section{Results}

Trial Populations. Most of the HCC patients were men (83.6\%) and carriers of hepatitis B virus (95.5\%), had large tumor size $(75.4 \%)$, a single tumor nodule at the time of resection $(60.0 \%)$, grade III or IV tumors $(55.4 \%)$, no metastasis $(93.8 \%)$, no portal vein tumor thrombus (75.4\%), and no splenomegaly (72.3\%) (Table 1).

CYP2E1 Activity Was Elevated in Non-neoplastic Liver Tissue from HCC Patients. Using the enzyme velocity of CYP2E1 for DEN $\left(\mathrm{V}_{\mathrm{DEN}}\right)$ in human liver microsomes, we observed higher CYP2E1 activity in the HCC patients than in the control subjects $(P=6.95 \mathrm{E}-14)$, which was similar to the pattern observed for probe metabolism $(P=2.48 \mathrm{E}-16)$. Additionally, there was a strong correlation in values of $\mathrm{V}_{\mathrm{DEN}}$ and $\mathrm{V}_{\mathrm{CZX}}$ in the control subjects and HCC patients (Fig. 1A). Therefore, DEN is mainly metabolized by CYP2E1 in human liver microsomes. Because CYP2E1 activity in control subjects was not normally distributed, the one-sided $95 \%$ reference value was calculated by adopting the percentile method. The data showed CYP2E1 positivity in $43.3 \%$ (29 of 67 ) of the HCC patients analyzed, albeit with various levels of activity. In addition, analysis of the effect of demographic and clinicopathologic characteristics for the $\mathrm{V}_{\mathrm{DEN}}$ showed that CYP2E1 activity was not affected by the aforementioned parameters (Fig. 1B). The correlation analysis showed that there was no correlation between CYP2E1 content and $\mathrm{V}_{\mathrm{DEN}}$, whether in control subjects or HCC patients (Fig. 1C).

Altogether, our findings that CYP2E1-mediated DEN metabolic activity was increased and clinicopathologic characteristics had no effect on CYP2E1-mediated DEN metabolic activity in HCC patients indicate that higher CYP2E1 activity might correlate with hepatocarcinogenesis induced by DEN.

Higher CYP2E1 Constitutive Activity Correlated with Hepatocarcinogenesis Induced by DEN. To test the hypothesis based on the human data, the causal relationship between CYP2E1 constitutive activity and hepatocarcinogenesis was explored using the SD rat liver tumor model induced by DEN.

At week 19 the tumor incidence was 64.9\% (24 of 37) in liver tumor models. Macroscopically, there were significant differences in liver weight (percentage body weight), nodule numbers, and size of nodules in control, nontumor, and tumor groups (Fig. 2, A and B). Histopathologic examination revealed that control liver demonstrated a structured homomorphic architecture with distinctly arranged hepatocytes; nontumor livers were characterized by centrilobular atypia and multiple larger dysplastic foci, and tumor livers displayed thickened trabeculae and a focal adenoid pattern, as well as
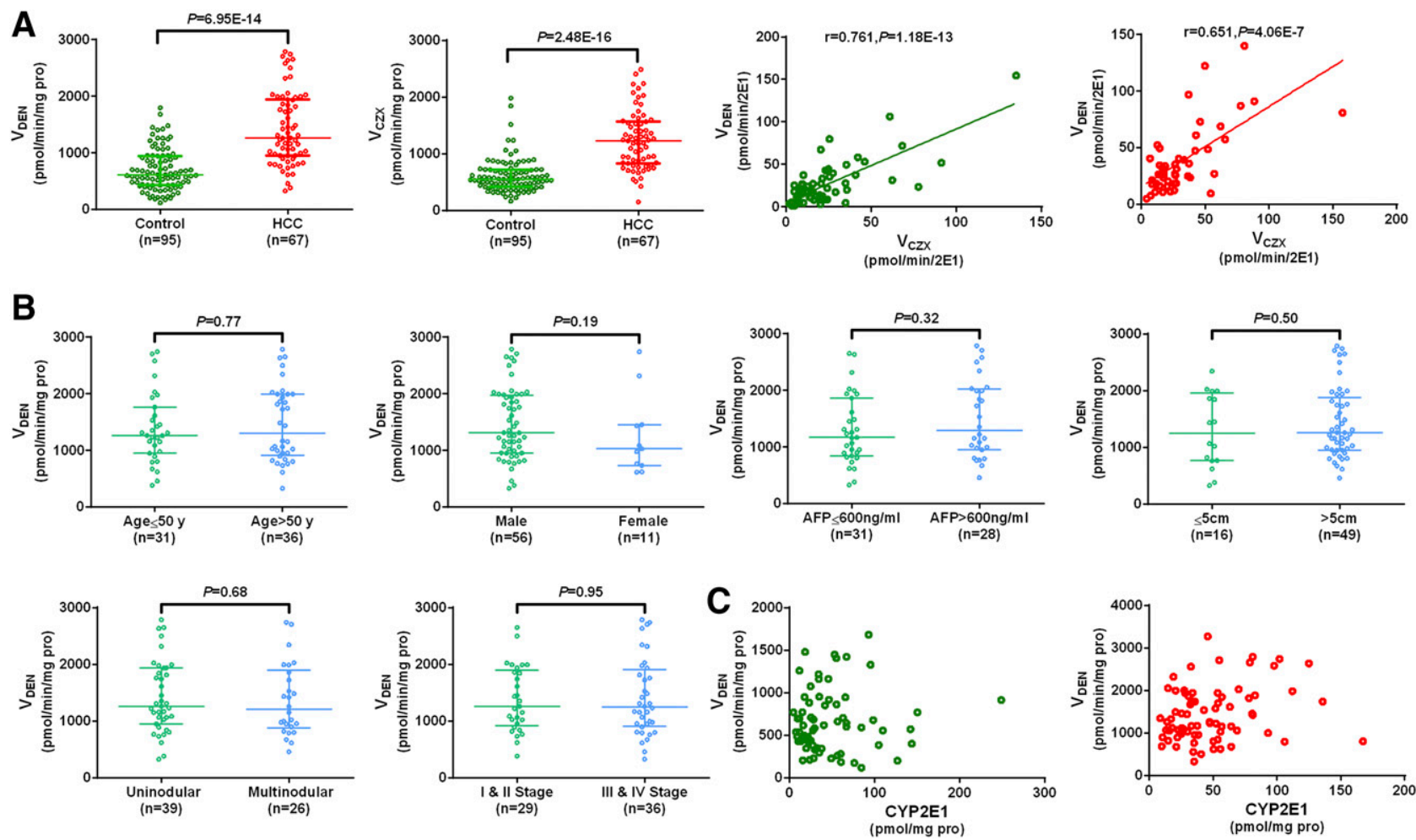

Fig. 1. CYP2E1 activity in control subjects $(n=95)$ and HCC patients $(n=67)$. (A) DEN is predominantly metabolized by CYP2E1, and CYP2E1 activity increased in HCC patients. (B) Clinicopathologic parameters do not affect CYP2E1 activity. (C) There was no correlation between CYP2E1 content and $\mathrm{V}_{\mathrm{DEN}}$. Green circles represent control subjects, and red circles represent HCC patients in (A) and (C). Data are expressed as the median with interquartile range by Mann-Whitney $U$ test, where significant correlations were determined using two-tailed Pearson correlation calculations. AFP, $\alpha$-fetoprotein. 
A
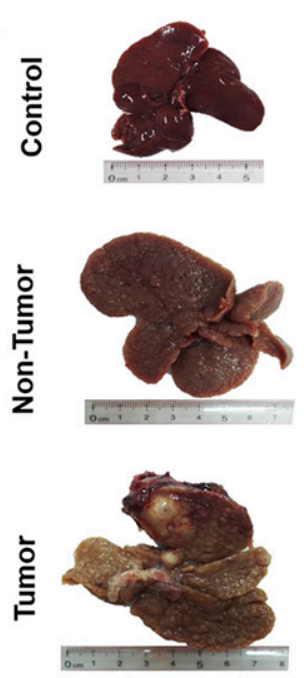

C
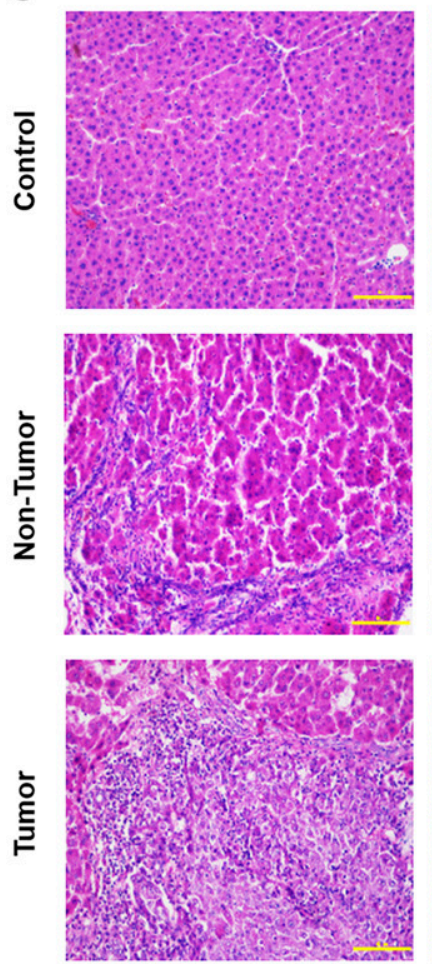
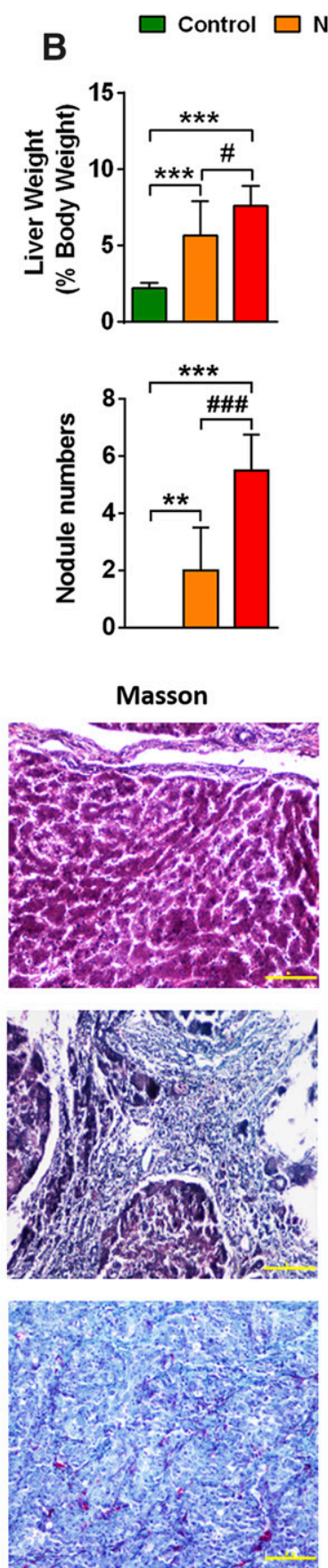
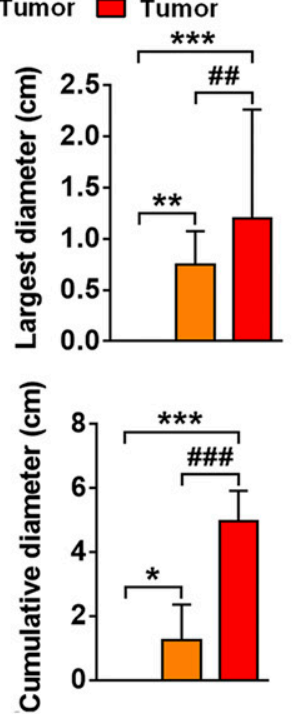

Ki67
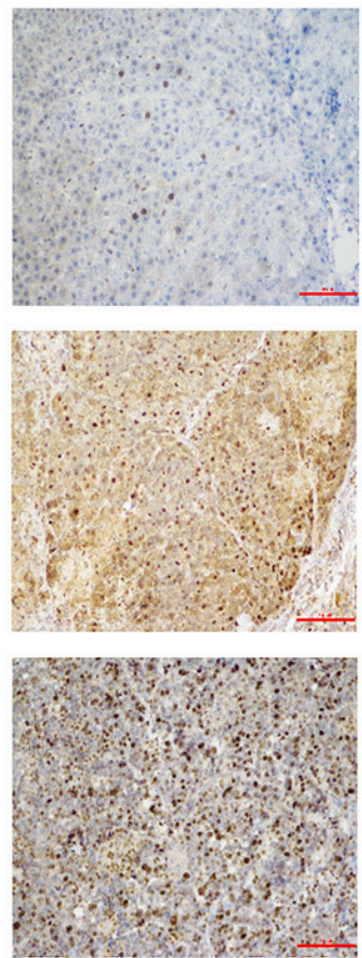
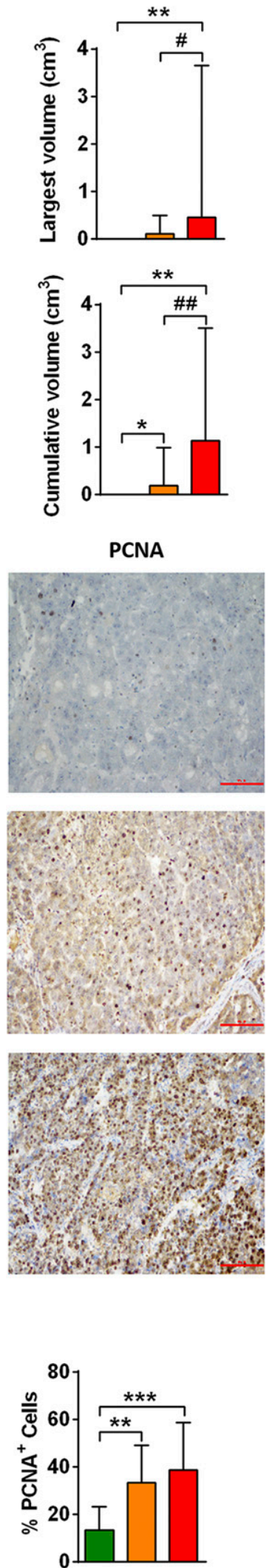

Fig. 2. Macroscopic and microscopic findings on control $(n=11)$ and DEN-induced hepatocarcinogenesis (nontumor, $n=13$; tumor, $n=24)$ in male rats. (A) Representative rat livers at week 19. (B) Liver weight, nodule numbers, and size of nodules at week 19. Data are expressed as the median with interquartile range $\left({ }^{*} P<0.05,{ }^{* *} P<0.01\right.$, and ${ }^{* * *} P<0.001$ compared with control group; ${ }^{\#} P<0.05$, ${ }^{\# \#} P<0.01$, and ${ }^{\# \# \#} P<0.001$ compared with nontumor group; Kruskal-Wallis test followed by Dunn's test). (C) Representative H\&E and Masson's trichrome staining of liver tissue (scale bar, $50 \mu \mathrm{m}$ ) and representative photomicrographs of liver sections were stained for Ki67 and PCNA (scale bar, 100 $\mu \mathrm{m}$ ). (D) H\&E stains of 
enhanced cytologic atypia and mitotic figures (Fig. 2, C and D, left panels). Hepatocyte proliferation was assessed by immunohistochemical staining for PCNA and Ki67 (Fig. 2, C and D, right panels). The results showed that hepatocyte proliferation was significantly increased in liver tumor models.

Beginning with the establishment of liver tumor models (at week 0), the CYP2E1 constitutive activity of each rat was determined by measuring toxicokinetic parameters $\left(\mathrm{t}_{1 / 2}\right.$, $\mathrm{CL} / \mathrm{F}$, and $\mathrm{AUC}_{0-\mathrm{t}}$ ) of DEN. We found that CYP2E1 constitutive activity in rats developing liver tumors was observably higher than that in the control group (Fig. 3, A and B). The higher constitutive activity was associated with higher tumor incidence (Fig. 3C). Further, higher CYP2E1 constitutive activity led to more severe tumorigenesis (nodule numbers and size), and correlation analysis indicated that the CYP2E1 constitutive activity was significantly positively correlated with nodule numbers and size of nodules in liver tumor models (Fig. 3, D-F).

Taken together, these data showed that normal rats with higher CYP2E1 activity have a greater likelihood of tumorigenesis, which suggests that higher CYP2E1 activity at week 0 (normal stage) correlates with hepatocarcinogenesis induced by DEN.

Inhibition of CYP2E1 Prevented DEN-Induced Hepatocarcinogenesis. To further confirm the possibility that higher CYP2E1 activity correlates with hepatocarcinogenesis induced by DEN, CMZ, known as a CYP2E1 inhibitor in vivo and in vitro, was used in this intervention experiment to examine the effect of inhibition of CYP2E1 activity on hepatocarcinogenesis using the SD rat liver tumor model induced by DEN.

After administration of CMZ (10 or $100 \mathrm{mg} / \mathrm{kg}$ ), liver weight (percentage body weight), nodule numbers, size of nodules, and tumor incidence at week 19 are shown (Fig. 4, A and $\mathrm{B}$ ). The results indicated that tumor incidence, nodule numbers, and size of the nodules were dramatically reduced in the $100 \mathrm{mg} / \mathrm{kg}$ group as compared with the model (control) group. For the $10 \mathrm{mg} / \mathrm{kg}$ group, $100 \mathrm{mg} / \mathrm{kg}$ group, and model group, the number of rats showing tumors were $6(50.0 \%)$, $1(10.0 \%)$, and $24(64.9 \%)$, respectively; the nodule numbers were $2(0 \sim 7), 1(0 \sim 3)$, and $4(0 \sim 9)$, respectively; the sizes of nodules (cumulative volume) were 0.38 (0 9.21), 0.063 $(0 \sim 1.51)$, and $0.69(0 \sim 13.69) \mathrm{cm}^{3}$, respectively. In addition, CMZ (100 mg/kg) could markedly suppress hepatocellular malignant proliferation in DEN-treated rats, as evidenced by a $33.9 \%$ decrease in the amount of PCNA-positive cells (Fig. $4, \mathrm{C}$ and $\mathrm{D})$. These data were corroborated by Ki67 staining (Fig. 4, C and D). These findings suggest that CMZ (100 mg/kg) decreased hepatocyte proliferation, liver injury, and hepatocarcinogenesis.

Simultaneously, the CYP2E1 activity in vivo with or without CMZ treatment was determined using toxicokinetic parameters. Indeed, the plasma concentration profiles, $\mathrm{t}_{1 / 2}$, $\mathrm{AUC}_{0-\mathrm{t}}$, and $\mathrm{CL} / \mathrm{F}$ with or without CMZ treatment in the DENinduced liver tumor model rats were significantly different (Fig. 4, E and F). For the $10 \mathrm{mg} / \mathrm{kg}$ group, $100 \mathrm{mg} / \mathrm{kg}$ group, and model group, the values of CL/F were $0.12(0.10 \sim 0.14), 0.063$ (0.051 0.075), and $0.19(0.15 \sim 0.28) \mathrm{l} / \mathrm{h} / \mathrm{kg}$, respectively; the values of $\mathrm{AUC}_{0-\mathrm{t}}$ were $395.6 \quad(363.8 \sim 496.5), \quad 753.5$ (668.3 893.7), and $234.5(158.1 \sim 285.5) \mathrm{mg} / \mathrm{l}^{*} \mathrm{~h}$, respectively; the values of $\mathrm{t}_{1 / 2}$ were 3.56 (3.02 4.38), 4.41 (4.03 12.78), and $2.78(0.79 \sim 3.92)$ hours, respectively (Fig. $4 \mathrm{~F})$. In addition, the inhibition by CMZ of CYP2E1 activity yielded a dosedependent inhibition pattern, as verified by a self-controlled test (Table 2), which was consistent with the aforementioned findings.

Taken together, CMZ may decrease hepatocarcinogenesis by inhibiting CYP2E1 activity, suggesting that inhibition of CYP2E1 activity could prevent hepatocarcinogenesis induced by DEN.

\section{Discussion}

In this study, we found that CYP2E1-mediated DEN metabolic activity significantly increased in non-neoplastic liver tissue from HCC patients with a $43.3 \%$ positive rate. Using the SD rat liver tumor model induced by DEN, the causal relationship of CYP2E1 activity and hepatocarcinogenesis was confirmed with evidence that CYP2E1 constitutive activity (at normal stage) was positively correlated with tumor incidence and severity of tumorigenesis (nodule numbers and size); simultaneously, inhibition of CYP2E1 activity decreased hepatocyte proliferation, liver injury, and liver carcinogenesis. Taken together, these data argue that higher CYP2E1 activity correlates with hepatocarcinogenesis induced by DEN.

HCC is diagnosed in more than half a million people worldwide and is associated with a poor prognosis (ElSerag, 2011; Nault, 2017). As a level I carcinogen, DEN is recognized as a susceptibility factor for hepatocarcinogenesis in experimental animals and in humans and has been found widely in the environment and numerous products (Ko et al., 1987; Gonzalez, 2001; Garcia-Suastegui et al., 2017). DEN oxidation initially by cytochrome P450 enzymes may be critical to exert its genotoxicity. Although other cytochrome P450 enzymes (CYP2A6 and CYP3A4) are involved in the metabolic activation of $\mathrm{DEN}$ in vitro (Camus et al., 1993; Bellec et al., 1996), the contribution of CYP2E1 is larger than that of other cytochrome P450 enzymes (Yoo et al., 1990; Yamazaki et al., 1992; Kushida et al., 2000). Furthermore, CYP2E1 is also mainly involved in the metabolic activation of DEN in vivo (Verna et al., 1996; Hengstler et al., 2003; Kang et al., 2007; Zhang et al., 2013; Bergmann et al., 2017). In the present study, we found that there was a positive correlation in values of $V_{D E N}$ and $\mathrm{V}_{\mathrm{CZX}}$ (CYP2E1 probe substrate) in the control subjects and HCC patients. Therefore, DEN should be mainly metabolized by CYP2E1.

For patients with simple hepatic cirrhosis, CYP2E1mediated probe (CZX) metabolic activity in vivo and CYP2E1-mediated $N, N$-dimethylnitrosamine $N$-demethylase activity in vitro were clearly decreased or unchanged (George

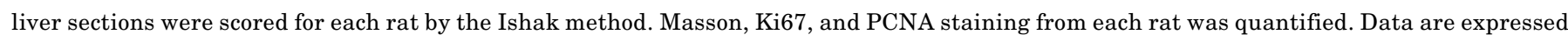

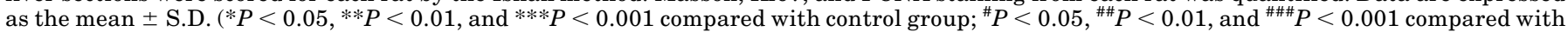
nontumor group; one-way analysis of variance with Tamhane's T2 analysis).
} 

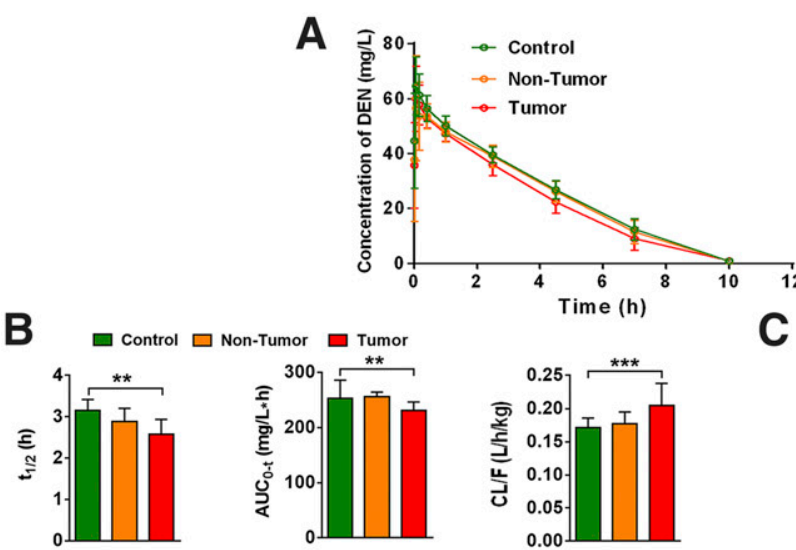

C
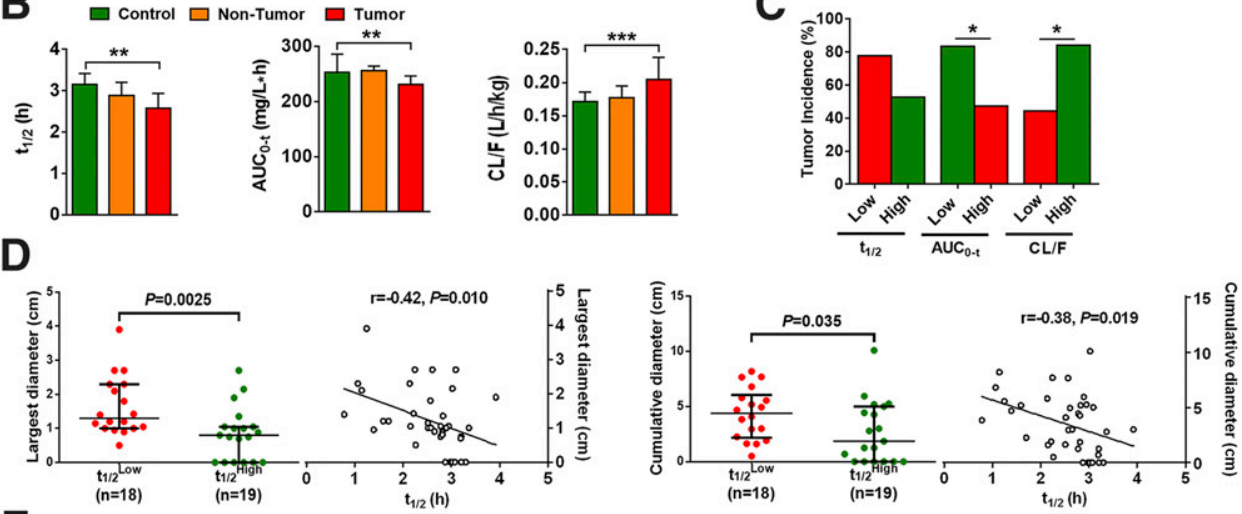

E
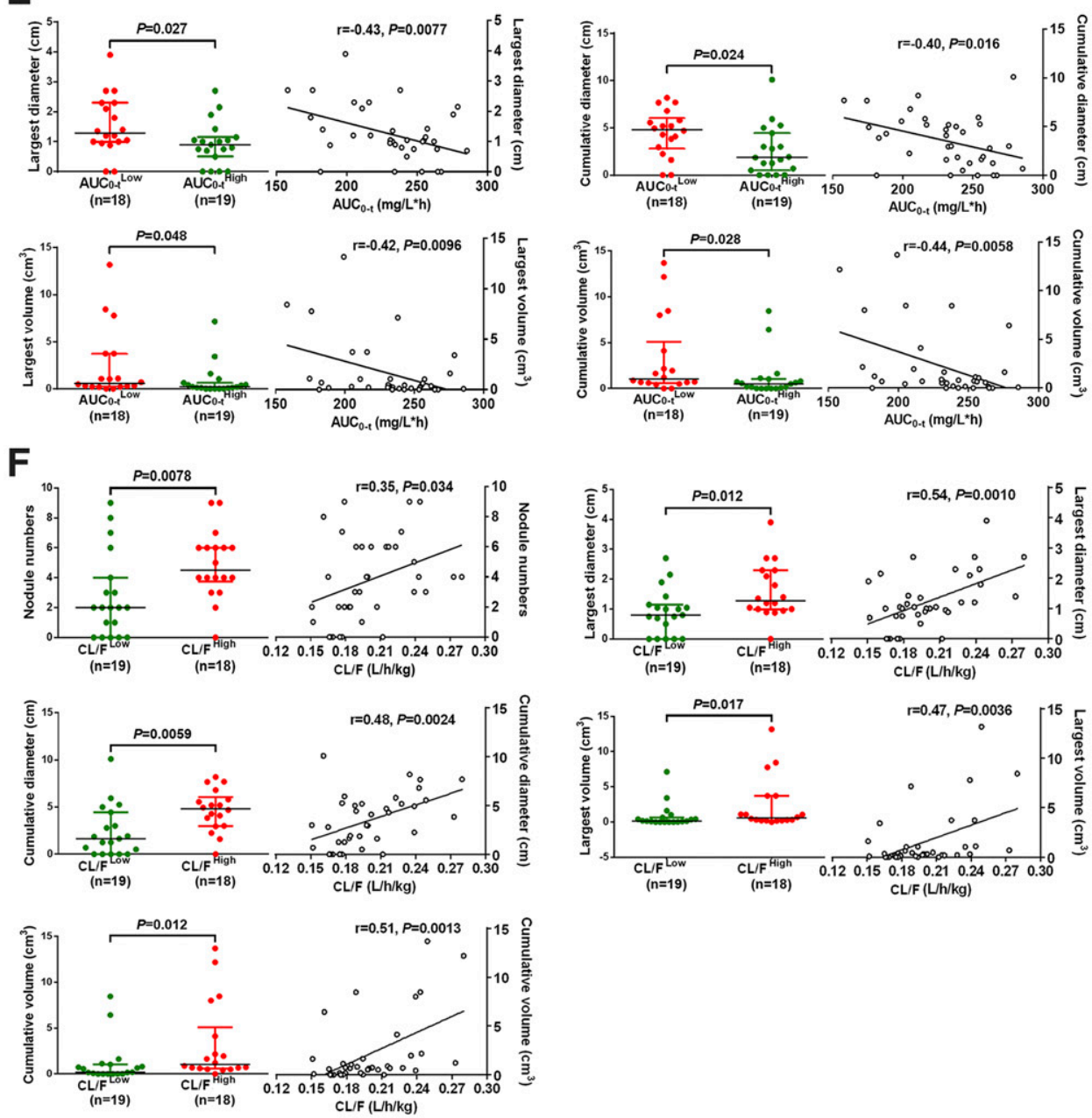

Fig. 3. CYP2E1 constitutive activity is associated with risk of liver tumor. Control group $(n=20)$, nontumor $(n=13)$, tumor $(n$ $=24$ ). (A) Time course of the plasma concentration of DEN in the DEN-induced HCC model at week 0. (B) Toxicokinetic parameters of DEN $(50 \mathrm{mg} / \mathrm{kg})$ after i.p. administration in the control, nontumor, and tumor groups at week 0. Data are expressed as the median with interquartile range $(* P<0.05, * * P<0.01$, and $* * * P<$ 0.001 compared with control group; KruskalWallis test followed by Dunn's test). (C) The incidence of liver tumor induced by DEN in rats was influenced by CYP2E1 constitutive activity (low, $n=18$; high, $n=19$ ). $* P<0.05$ compared with low group; $\chi^{2}$ test. (D-F) CYP2E1 constitutive activity expressed by $t_{1 / 2}, A C_{0-t}$, and CL/F of DEN is associated with severe tumorigenesis (nodule numbers and size). Mann-Whitney $U$ test and twotailed Pearson correlation calculations were used. et al., 1995; Frye et al., 2006). However, our previous and present studies found that CYP2E1-mediated probe and DEN activities were both markedly increased in HCC patients. In the present study, we also found that age, gender, and clinicopathologic characteristics had no effect on CYP2E1mediated DEN metabolic activity in $\mathrm{HCC}$ patients. In 
A

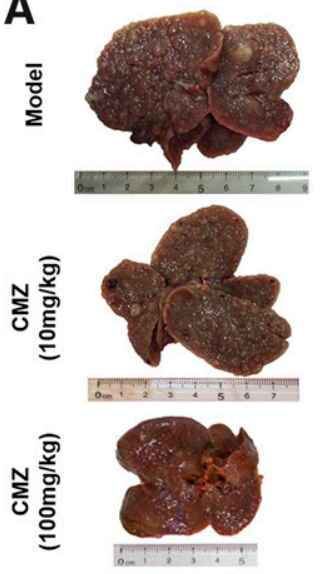

C
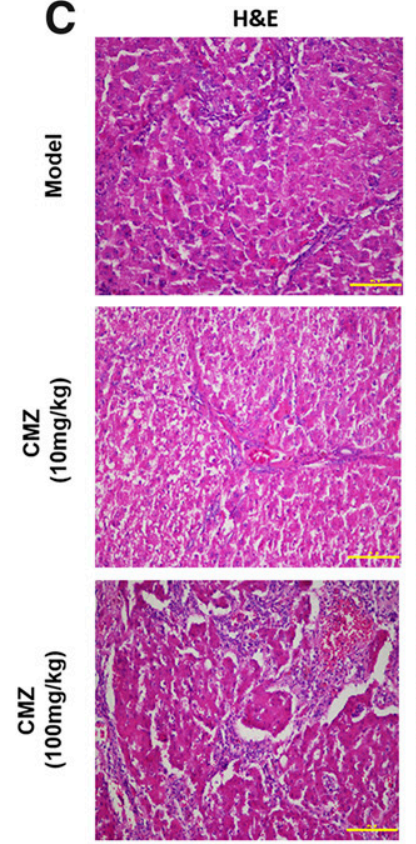
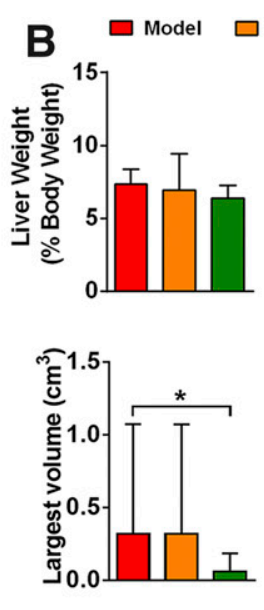
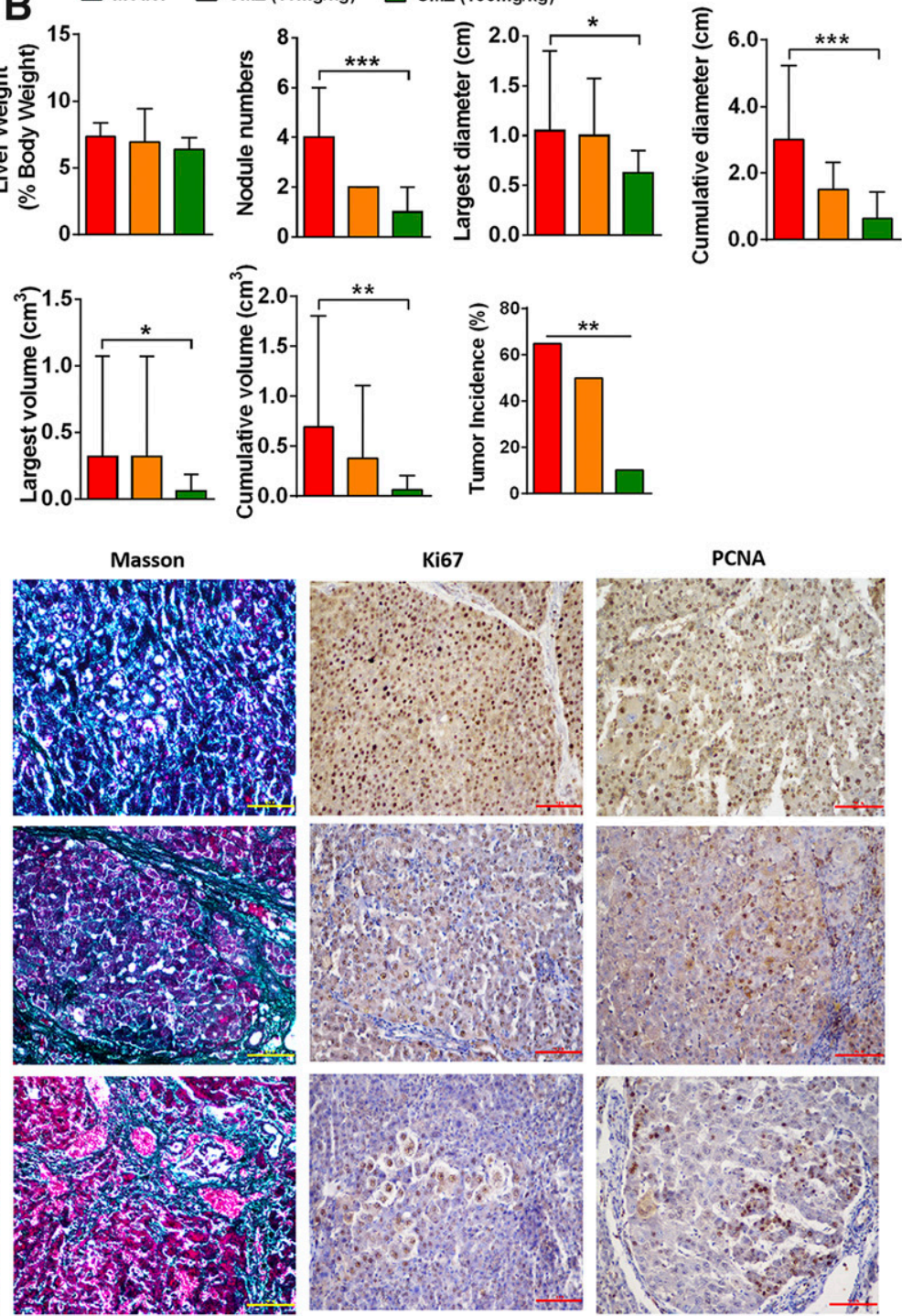

D
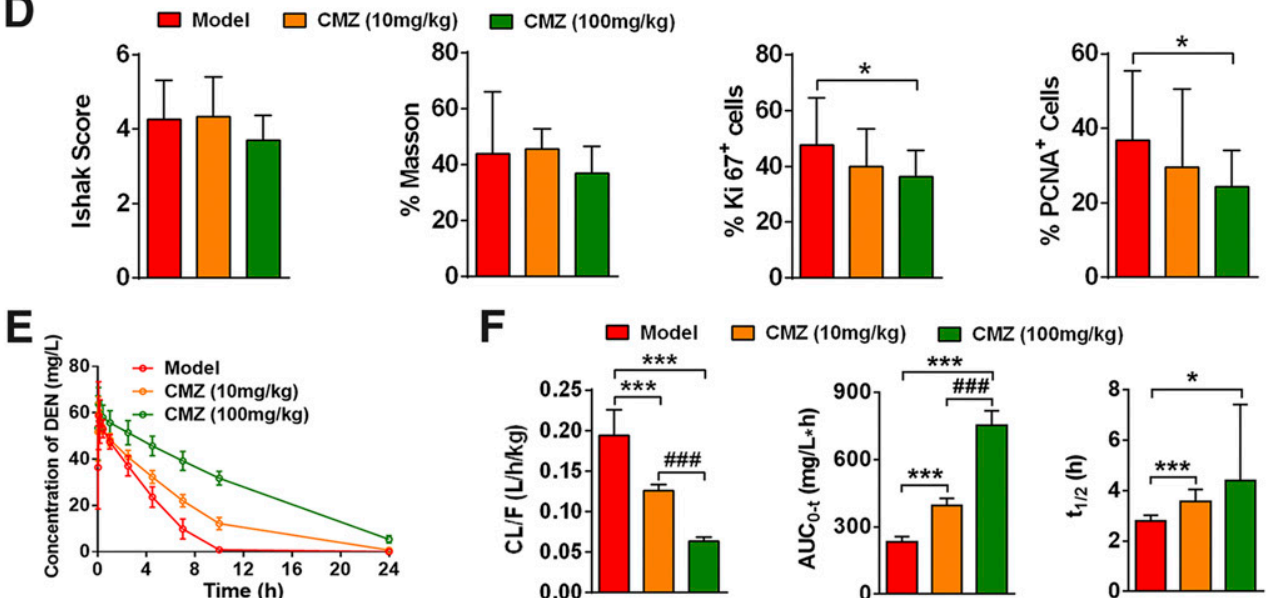

$\mathbf{F}$
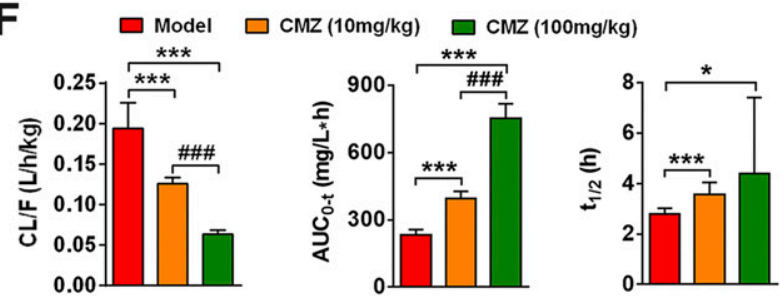

Fig. 4. Inhibition CYP2E1 activity suppressed by CMZ prevented DEN-induced liver tumor development. Model group ( $n=37), 10 \mathrm{mg} / \mathrm{kg}$ CMZ $(n=12), 100 \mathrm{mg} / \mathrm{kg} \mathrm{CMZ}(n=10)$. (A) Representative rat livers at week 19. (B) Liver weight, nodule numbers, size of nodules, and tumor incidence at week 19. (C) Representative H\&E and Masson's trichrome staining of liver tissue (scale bar, $100 \mu \mathrm{m}$ ) and representative photomicrographs of liver sections were stained for Ki67 and PCNA (scale bar, $100 \mu \mathrm{m}$ ). (D) H\&E stains of liver sections were scored from each rat by the Ishak method. Masson, Ki67, and PCNA staining from each rat was quantified. (E) Time course of the plasma concentration of DEN at week 0. (F) Toxicokinetic parameters of DEN in liver tumor models treated with saline or CMZ (10 or $100 \mathrm{mg} / \mathrm{kg}$ ). Rats received DEN (50 mg/kg) via intraperitoneal injection 
TABLE 2

Toxicokinetic parameters of DEN (50 mg/kg) before and after treatment with CMZ (10 or $100 \mathrm{mg} / \mathrm{kg})$ Group 1 was administered DEN (50 mg/kg) or DEN $(50 \mathrm{mg} / \mathrm{kg})+$ CMZ $(10 \mathrm{mg} / \mathrm{kg})$. Group 2 was administered DEN $(50 \mathrm{mg} / \mathrm{kg})$ or DEN $(50 \mathrm{mg} / \mathrm{kg})+\mathrm{CMZ}(100 \mathrm{mg} / \mathrm{kg})$.

\begin{tabular}{|c|c|c|c|}
\hline Group & $\mathrm{CL} / \mathrm{F}$ & $\mathrm{AUC}_{0-\mathrm{t}}$ & $\mathrm{t}_{1 / 2}$ \\
\hline & $l / h / k g$ & $m g / l * h$ & $h$ \\
\hline \multicolumn{4}{|l|}{ Group $1(n=12)$} \\
\hline DEN & $0.30(0.23 \sim 0.37)$ & $166.9(135.8 \sim 219.3)$ & $0.89(0.66 \sim 1.82)$ \\
\hline $\mathrm{DEN}+\mathrm{CMZ}$ & $0.12(0.10 \sim 0.14)^{* * *}$ & $395.6(363.8 \sim 496.5) * * *$ & $3.56(3.02 \sim 4.38)^{* * *}$ \\
\hline Inhibition ratio $(\%)$ & $58.47(39.56 \sim 66.78)$ & $58.33(39.91 \sim 66.21)$ & $72.49(46.06 \sim 82.00)$ \\
\hline \multicolumn{4}{|c|}{ Group $2(n=10)$} \\
\hline DEN & $0.35(0.24 \sim 0.40)$ & $143.3(124.7 \sim 208.8)$ & $0.81(0.67 \sim 1.45)$ \\
\hline $\mathrm{DEN}+\mathrm{CMZ}$ & $0.06(0.05 \sim 0.08) * * *, \# \# \#$ & 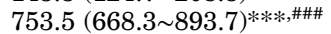 & 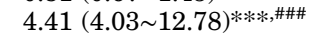 \\
\hline Inhibition ratio $(\%)$ & $80.72(72.69 \sim 85.54)$ & $79.69(72.75 \sim 85.52)$ & $82.90(77.68 \sim 94.80)$ \\
\hline
\end{tabular}

*** $P<0.001$ compared with DEN group, by Paired $t$ test; ${ }^{\# \# ~} P<0.001$ compared with CMZ (10 mg/kg) group, by Mann-Whitney $U$ test.

addition, there is considerable evidence to support the view that DEN is one of the most potent chemical carcinogens for hepatocarcinogenesis in experimental animals and is present widely in the environment (Bartsch and Montesano, 1984; Hoffmann and Hecht, 1985; Ko et al., 1987; Mirvish, 1995; Gonzalez, 2001; Garcia-Suastegui et al., 2017). These observations raise the question as to whether higher CYP2E1 activity correlates with hepatocarcinogenesis induced by DEN. In light of this, inhibition of CYP2E1 might be useful for treatment of hepatocarcinogenesis induced by DEN.

Of particular relevance, Kang et al. (2007) found that Cyp2e1-null mice show lower tumor incidence and multiplicity compared with wild-type mice in the DEN-induced hepatocarcinogenesis model. In addition, the deletion of the CYP2E1 gene also decreased the development of alcoholic steatohepatitis (Abdelmegeed et al., 2013), nonalcoholic steatohepatitis (Seth et al., 2014), and fast food-mediated hepatofibrosis (Abdelmegeed et al., 2012). Although the pathologic role of CYP2E1 in liver disease has been suggested previously, none of the previous studies explored the relationship between CYP2E1 activity and hepatocarcinogenesis. Due to the lack of correlation between CYP2E1 content and its activity in the current study, it is very important to measure CYP2E1 activity rather than its content in hepatocarcinogenesis.

Because DEN was mainly metabolized by CYP2E1 in vivo (Verna et al., 1996; Hengstler et al., 2003; Kang et al., 2007; Zhang et al., 2013; Bergmann et al., 2017), CL/F was the volume of plasma containing DEN that was removed from the body per unit time, $t_{1 / 2}$ referred to the time required to eliminate half of DEN in the body, and $\mathrm{AUC}_{0-\mathrm{t}}$ reflected the amount of DEN entering the blood circulation; therefore, the CYP2E1 activity at week 0 was determined by measuring toxicokinetic parameters $\left(\mathrm{CL} / \mathrm{F}, \mathrm{AUC}_{0-\mathrm{t}}\right.$, and $\left.\mathrm{t}_{1 / 2}\right)$ of $\mathrm{DEN}$ to keep the rat alive and complete the liver tumor model. Our data showed that CYP2E1 constitutive activity was positively correlated with tumor incidence and severity of liver tumor (nodule numbers and size), and higher CYP2E1 constitutive activity resulted in a greater likelihood of tumorigenesis, which confirmed the possibility that higher CYP2E1 activity correlates with hepatocarcinogenesis induced by DEN.

To further verify the hypothesis based on the human data, the effect of inhibition of CYP2E1 activity on DEN-induced hepatocarcinogenesis was evaluated. CMZ, previously described as an inhibitor of rat and human CYP2E1 both in vitro and in vivo (Chen et al., 2014; Stresser et al., 2016), was used in this intervention experiment. Although CYP2E1 activity was inhibited by about $80 \%$ by CMZ at $100 \mathrm{mg} / \mathrm{kg}$, this inhibition could decrease, but not stop, hepatocarcinogenesis. The most likely reasons are that the extent of inhibition of CMZ at this dose and the intermittent dosing schedule are insufficient to maintain full inhibition of CYP2E1. We tried to increase the CMZ dose, but the idea was dropped due to the toxicity of this chemical. Therefore, safe and efficient inhibitors of CYP2E1 will be needed to pursue this line of investigation. Nonetheless, inhibition of CYP2E1 activity decreased hepatocyte proliferation, liver injury, and liver carcinogenesis, providing support for the possibility that higher CYP2E1 activity correlates with hepatocarcinogenesis induced by DEN.

Multiple risk factors (e.g., HBV, hepatitis $\mathrm{C}$ virus, alcohol, nonalcoholic fatty liver disease, diabetes, tobacco, etc.) also contribute to HCC. A frequent risk factor for HCC is chronic HBV infection, and $95.5 \%$ of HCC patients were carriers of HBV in the present study, which indicates that HBV and high CYP2E1 activity might work synergistically to increase the risk of HCC.

In conclusion, we confirmed that higher CYP2E1 activity correlates with hepatocarcinogenesis induced by DEN based on the findings that HCC patients had higher CYP2E1 activity, and that higher CYP2E1 constitutive activity results in a greater likelihood of hepatocarcinogenesis induced by DEN and inhibition of CYP2E1 activity could prevent hepatocarcinogenesis induced by DEN. As a consequence, these findings might be helpful for screening high-risk individuals for HCC and for identifying new preventative strategies for hepatocarcinogenesis induced by DEN.

together with CMZ, and DEN was given immediately after the injection of CMZ. Data are expressed as the median with interquartile range $[* P<$ $0.05,{ }^{*} P<0.01$, and ${ }^{* * *} P<0.001$ compared with model group; ${ }^{\#} P<0.05$, \#\# $P<0.01$, and ${ }^{\# \# \# ~} P<0.001$ compared with $\mathrm{CMZ}$ (10 mg/kg) group; Kruskal-Wallis test followed by Dunn's test]. 


\section{Authorship Contributions}

Participated in research design: Qiao.

Conducted experiments: J. Gao, Z. Wang, G.-J. Wang, H.-X. Zhang,

N. Gao.

Contributed new reagents or analytic tools: J. Wang, C.-E. Wang,

Chang, Fang.

Performed data analysis: J. Gao, Y.-F. Zhang, Zhou, Jin.

Wrote or contributed to the writing of the manuscript: J. Gao, Qiao.

\section{References}

Abdelmegeed MA, Banerjee A, Jang S, Yoo SH, Yun JW, Gonzalez FJ, Keshavarzian A, and Song BJ (2013) CYP2E1 potentiates binge alcohol-induced gut leakiness, steatohepatitis, and apoptosis. Free Radic Biol Med 65:1238-1245.

Abdelmegeed MA, Banerjee A, Yoo SH, Jang S, Gonzalez FJ, and Song BJ (2012) Critical role of cytochrome P450 2E1 (CYP2E1) in the development of high fatinduced non-alcoholic steatohepatitis. J Hepatol 57:860-866.

Abu Dayyeh BK, Yang M, Fuchs BC, Karl DL, Yamada S, Sninsky JJ, O'Brien TR, Dienstag JL, Tanabe KK, and Chung RT; HALT-C Trial Group (2011) A functional polymorphism in the epidermal growth factor gene is associated with risk for hepatocellular carcinoma. Gastroenterology 141:141-149.

Bartsch H and Montesano R (1984) Relevance of nitrosamines to human cancer. Carcinogenesis 5:1381-1393.

Bellec G, Dréano Y, Lozach P, Ménez JF, and Berthou F (1996) Cytochrome P450 metabolic dealkylation of nine $\mathrm{N}$-nitrosodialkylamines by human liver microsomes Carcinogenesis 17:2029-2034

Bergmann J, Müller M, Baumann N, Reichert M, Heneweer C, Bolik J, Lücke K, Gruber S, Carambia A, Boretius S, et al. (2017) IL-6 trans-signaling is essential for the development of hepatocellular carcinoma in mice. Hepatology 65:89-103.

Boccia S, Miele L, Panic N, Turati F, Arzani D, Cefalo C, Amore R, Bulajic M, Pompili M, Rapaccini G, et al. (2015) The effect of CYP, GST, and SULT polymorphisms and their interaction with smoking on the risk of hepatocellular carcinoma. BioMed Res Int 2015:179867.

Bosetti C, Levi F, Boffetta P, Lucchini F, Negri E, and La Vecchia C (2008) Trends in mortality from hepatocellular carcinoma in Europe, 1980-2004. Hepatology 48 137-145.

Bradford MM (1976) A rapid and sensitive method for the quantitation of microgram quantities of protein utilizing the principle of protein-dye binding. Anal Biochem 72:248-254.

Camus AM, Geneste O, Honkakoski P, Béréziat JC, Henderson CJ, Wolf CR, Bartsch $\mathrm{H}$, and Lang MA (1993) High variability of nitrosamine metabolism among individuals: role of cytochromes $\mathrm{P} 4502 \mathrm{~A} 6$ and $2 \mathrm{E} 1$ in the dealkylation of $\mathrm{N}$-nitrosodimethylamine and N-nitrosodiethylamine in mice and humans. $\mathrm{Mol}$ Carcinog 7:268-275.

Chen YY, Zhang CL, Zhao XL, Xie KQ, and Zeng T (2014) Inhibition of cytochrome P4502E1 by chlormethiazole attenuated acute ethanol-induced fatty liver. Chem Biol Interact 222:18-26.

Druesne-Pecollo N, Tehard B, Mallet Y, Gerber M, Norat T, Hercberg S, and LatinoMartel P (2009) Alcohol and genetic polymorphisms: effect on risk of alcoholrelated cancer. Lancet Oncol 10:173-180.

El-Serag HB (2011) Hepatocellular carcinoma. N Engl J Med 365:1118-1127.

El-Serag HB and Rudolph KL (2007) Hepatocellular carcinoma: epidemiology and molecular carcinogenesis. Gastroenterology 132:2557-2576.

Ferlay J, Shin HR, Bray F, Forman D, Mathers C, and Parkin DM (2010) Estimates of worldwide burden of cancer in 2008: GLOBOCAN 2008. Int $J$ Cancer 127: $2893-2917$

Frye RF, Zgheib NK, Matzke GR, Chaves-Gnecco D, Rabinovitz M, Shaikh OS, and Branch RA (2006) Liver disease selectively modulates cytochrome P450-mediated metabolism. Clin Pharmacol Ther 80:235-245.

Gao J, Zhou J, He XP, Zhang YF, Gao N, Tian X, Fang Y, Wen Q, Jia LJ, Jin H, et al. (2016a) Changes in cytochrome P450s-mediated drug clearance in patients with hepatocellular carcinoma in vitro and in vivo: a bottom-up approach. Oncotarget 7 : 28612-28623.

Gao N, Tian X, Fang Y, Zhou J, Zhang H, Wen Q, Jia L, Gao J, Sun B, Wei J, et al. (2016b) Gene polymorphisms and contents of cytochrome P450s have only limited effects on metabolic activities in human liver microsomes. Eur J Pharm Sci 92 86-97.

García-Suástegui WA, Ramos-Chávez LA, Rubio-Osornio M, Calvillo-Velasco M, Atzin-Méndez JA, Guevara J, and Silva-Adaya D (2017) The role of CYP2E1 in the drug metabolism or bioactivation in the brain. Oxid Med Cell Longev 2017: 4680732

George J, Murray M, Byth K, and Farrell GC (1995) Differential alterations of cytochrome $\mathrm{P} 450$ proteins in livers from patients with severe chronic liver disease. Hepatology 21:120-128.

Gonzalez FJ (2001) The use of gene knockout mice to unravel the mechanisms of toxicity and chemical carcinogenesis. Toxicol Lett 120:199-208.

Gonzalez FJ (2005) Role of cytochromes P450 in chemical toxicity and oxidative stress: studies with CYP2E1. Mutat Res 569:101-110.

Guengerich FP, Kim DH, and Iwasaki M (1991) Role of human cytochrome P-450 IIE1 in the oxidation of many low molecular weight cancer suspects. Chem Res Toxicol 4:168-179.

Hengstler JG, Bogdanffy MS, Bolt HM, and Oesch F (2003) Challenging dogma: thresholds for genotoxic carcinogens? The case of vinyl acetate. Annu Rev Pharmacol Toxicol 43:485-520.

Herrmann SS, Granby K, and Duedahl-Olesen L (2015) Formation and mitigation of $\mathrm{N}$-nitrosamines in nitrite preserved cooked sausages. Food Chem 174:516-526.
Hoffmann D and Hecht SS (1985) Nicotine-derived N-nitrosamines and tobaccorelated cancer: current status and future directions. Cancer Res 45:935-944.

Ishak KG (1994) Chronic hepatitis: morphology and nomenclature. Mod Pathol 7 690-713.

Kang JS, Wanibuchi H, Morimura K, Gonzalez FJ, and Fukushima S (2007) Role of CYP2E1 in diethylnitrosamine-induced hepatocarcinogenesis in vivo. Cancer Res 67:11141-11146.

Kim H, Hong MK, Choi H, Moon HS, and Lee HJ (2015) Chemopreventive effects of korean red ginseng extract on rat hepatocarcinogenesis. J Cancer 6:1-8.

Ko IY, Park SS, Song BJ, Patten C, Tan YZ, Hah YC, Yang CS, and Gelboin HV (1987) Monoclonal antibodies to ethanol-induced rat liver cytochrome P-450 that metabolizes aniline and nitrosamines. Cancer Res 47:3101-3109.

Kushida H, Fujita K, Suzuki A, Yamada M, Endo T, Nohmi T, and Kamataki T (2000) Metabolic activation of $\mathrm{N}$-alkylnitrosamines in genetically engineered Salmonella typhimurium expressing CYP2E1 or CYP2A6 together with human NADPHcytochrome $\mathrm{P} 450$ reductase. Carcinogenesis 21:1227-1232.

Liu W, Tian F, Dai L, and Chai Y (2014) Cytochrome P450 2E1 gene polymorphism and alcohol drinking on the risk of hepatocellular carcinoma: a meta-analysis. Mol Biol Rep 41:7645-7650.

McClendon AK, Dean JL, Ertel A, Fu Z, Rivadeneira DB, Reed CA, Bourgo RJ, Witkiewicz A, Addya S, Mayhew CN, et al. (2011) RB and p53 cooperate to prevent liver tumorigenesis in response to tissue damage. Gastroenterology 141:1439-1450. Mirvish SS (1995) Role of N-nitroso compounds (NOC) and N-nitrosation in etiology of gastric, esophageal, nasopharyngeal and bladder cancer and contribution to cancer of known exposures to NOC. Cancer Lett 93:17-48.

Naito S, von Eschenbach AC, Giavazzi R, and Fidler IJ (1986) Growth and metastasis of tumor cells isolated from a human renal cell carcinoma implanted into different organs of nude mice. Cancer Res 46:4109-4115.

Nault JC (2017) The end of almost 10 years of negative RCTs in advanced hepatocellular carcinoma. Lancet 389:4-6.

Nault JC, Datta S, Imbeaud S, Franconi A, Mallet M, Couchy G, Letouzé E, Pilati C, Verret B, Blanc JF, et al. (2015) Recurrent AAV2-related insertional mutagenesis in human hepatocellular carcinomas. Nat Genet 47:1187-1193.

Seth RK, Das S, Kumar A, Chanda A, Kadiiska MB, Michelotti G, Manautou J, Diehl AM, and Chatterjee S (2014) CYP2E1-dependent and leptin-mediated hepatic CD57 expression on CD8+ T cells aid progression of environment-linked nonalcoholic steatohepatitis. Toxicol Appl Pharmacol 274:42-54.

Stresser DM, Perloff ES, Mason AK, Blanchard AP, Dehal SS, Creegan TP, Singh R, and Gangl ET (2016) Selective time- and NADPH-dependent inhibition of human CYP2E1 by clomethiazole. Drug Metab Dispos 44:1424-1430.

Su B, Luo T, Zhu J, Fu J, Zhao X, Chen L, Zhang H, Ren Y, Yu L, Yang X, et al. (2015) Interleukin-1及/Iinterleukin-1 receptor-associated kinase 1 inflammatory signaling contributes to persistent Gankyrin activation during hepatocarcinogenesis. Hep atology 61:585-597.

Trafalis DT, Panteli ES, Grivas A, Tsigris C, and Karamanakos PN (2010) CYP2E1 and risk of chemically mediated cancers. Expert Opin Drug Metab Toxicol 6:307-319.

Tsuda S, Murakami M, Matsusaka N, Kano K, Taniguchi K, and Sasaki YF (2001) DNA damage induced by red food dyes orally administered to pregnant and male mice. Toxicol Sci 61:92-99.

Verna L, Whysner J, and Williams GM (1996) N-nitrosodiethylamine mechanistic data and risk assessment: bioactivation, DNA-adduct formation, mutagenicity, and tumor initiation. Pharmacol Ther 71:57-81.

Wang Y, Yang H, Li L, Wang H, Zhang C, Yin G, and Zhu B (2010) Association between CYP2E1 genetic polymorphisms and lung cancer risk: a meta-analysis. Eur $J$ Cancer 46:758-764.

Yamazaki H, Oda Y, Funae Y, Imaoka S, Inui Y, Guengerich FP, and Shimada T (1992) Participation of rat liver cytochrome P450 2E1 in the activation of $\mathrm{N}$-nitrosodimethylamine and N-nitrosodiethylamine to products genotoxic in an acetyltransferase-overexpressing Salmonella typhimurium strain (NM2009). Carcinogenesis 13:979-985.

Yoo JS, Ishizaki H, and Yang CS (1990) Roles of cytochrome P450IIE1 in the dealkylation and denitrosation of $\mathrm{N}$-nitrosodimethylamine and $\mathrm{N}$-nitrosodiethylamine in rat liver microsomes. Carcinogenesis 11:2239-2243.

Yoshimoto S, Loo TM, Atarashi K, Kanda H, Sato S, Oyadomari S, Iwakura Y, Oshima K, Morita H, Hattori M, et al. (2013) Obesity-induced gut microbial metabolite promotes liver cancer through senescence secretome [published correction appears in Nature (2014) 506:396]. Nature 499:97-101.

Yu MW, Gladek-Yarborough A, Chiamprasert S, Santella RM, Liaw YF, and Chen CJ (1995) Cytochrome P450 2E1 and glutathione S-transferase M1 polymorphisms and susceptibility to hepatocellular carcinoma. Gastroenterology 109:1266-1273.

Zanger UM and Schwab M (2013) Cytochrome P450 enzymes in drug metabolism regulation of gene expression, enzyme activities, and impact of genetic variation. Pharmacol Ther 138:103-141.

Zhang CL, Zeng T, Zhao XL, and Xie KQ (2013) Garlic oil attenuated nitrosodiethylamine-induced hepatocarcinogenesis by modulating the metabolic activation and detoxification enzymes. Int J Biol Sci 9:237-245.

Zhang H, Gao N, Tian X, Liu T, Fang Y, Zhou J, Wen Q, Xu B, Qi B, Gao J, et al. (2015) Content and activity of human liver microsomal protein and prediction of individual hepatic clearance in vivo. Sci Rep 5:17671.

Zhou J, Wen Q, Li SF, Zhang YF, Gao N, Tian X, Fang Y, Gao J, Cui MZ, He XP, et al (2016) Significant change of cytochrome P450s activities in patients with hepatocellular carcinoma. Oncotarget 7:50612-50623.

Address correspondence to: Hai-Ling Qiao, Institute of Clinical Pharmacology, Zhengzhou University, 40 Daxue Road, Zhengzhou, Henan 450052, China. E-mail: qiaohl@zzu.edu.cn 